\title{
Inserção e integração dos smartphones nas aulas de Matemática: análise de uma prática pedagógica etnomatemática
}

\author{
André Gerstberger ${ }^{1}$ \\ Ieda Maria Giongo ${ }^{2}$
}

\begin{abstract}
RESUMO
O presente artigo socializa resultados decorrentes de uma prática pedagógica que teve como objetivo central integrar aparelhos de smartphones nas aulas de matemática em uma turma de nono ano de Ensino Fundamental de uma escola pública gaúcha. Os aportes teóricos que sustentam a investigação são relativos ao campo da etnomatemática em seus entrecruzamentos com ideias relativas à inserção de recursos computacionais nos processos de ensino na escola básica. Os materiais de pesquisa foram gerados a partir de filmagens das aulas e material escrito e produzido pelos estudantes. Metodologicamente, de cunho qualitativo e inspirações etnográficas, a pesquisa fez uso do método descritivo para análise dos dados emergentes. Os resultados apontaram possibilidades e limitações dos aplicativos e funções do smartphone na exploração de conteúdos usualmente presentes na Matemática Escolar.
\end{abstract}

PALAVRAS-CHAVE: Etnomatemática. Smartphone. Anos finais do Ensino Fundamental. Prática pedagógica.

Using and interating smartphones in math classes: analysis of an ethnomathematics teaching practice

\begin{abstract}
This article shares results from a teaching practice whose main purpose was integrating smartphones into math classes of a ninth-year group of a public primary school in RS (Brazil). The investigation was supported by the field of ethnomathematics and its intertwining with ideas regarding
\end{abstract}

\footnotetext{
${ }^{1}$ Mestre em Ensino de Ciências Exatas. Universidade de Cuiabá, Vera, Mato Grosso, Brasil. E-mail. andre_canelavera@hotmail.com.

2 Doutora em Educação. Universidade do Vale do Taquari - Univates, Lajeado, Rio Grande do Sul, Brasil. E-mail: igiongo@univates.br.
} 
including computer resources in the teaching processes of primary school. Research materials were generated from class filming and materials written and produced by students. The methodology used was qualitative, with ethnographic inspiration, using descriptive methods to analyze the emerging data. Results pointed to possibilities and limitations of smartphone applications and functions when exploring contents usually present in School Math.

KEYWORDS: Ethnomathematics. Smartphone. Late Years of Primary School. Teaching practice.

\section{Contextualização}

Diariamente é possível observar como os avanços tecnológicos estão conquistando em larga escala, adeptos dos mais variados níveis sociais e das diversas faixas etárias, principalmente quando se trata das tecnologias digitais. Entre os aparelhos digitais mais procurados encontram-se os aparelhos celulares, alguns chamados de smartphones, conhecidos também como "aparelhos inteligentes" devido a possuírem um sistema operacional capaz de executar diversas funções semelhantes às de um computador, porém minimizado no formato menor, mais prático e acessível.

De fato, é comum olharmos ao nosso redor - onde quer que estejamos e perceber que a maioria das pessoas possui ao menos um smartphone. Com diversos modelos disponíveis no mercado consumidor, os indivíduos procuram adquirir um aparelho que supra seus anseios e que lhe seja agradável, estética e fisicamente. Contém inúmeras funções como despertador/lembrete, calendário, agenda, bloco de notas, gravador de voz, câmera fotográfica e de vídeo, compartilhamento de arquivos por meio de bluetooth e nuvem, sensores ocular e de aproximação corporal, GPS/mapas, acesso à internet, assistir a vídeos, ouvir músicas, entre outras funções. Um exemplo prático de aplicativos é o Smart TV Remote $^{3}$, que substitui o

\footnotetext{
3 Disponível em: <http://www.techtudo.com.br/kits/melhores-aplicativos-para-controlar-a-tv-usando-osmartphone.html>.
} 
controle remoto da televisão digital, permitindo que o telespectador utilize os comandos da televisão por meio do aparelho celular. Outros aplicativos, como Smart $X^{4}$, auxiliam o motorista nas funções do carro, como ativar a trava elétrica, ligar/desligar painel, faróis, vidros elétricos, ligar e desligar o automóvel, utilizar a setas, entre outras funções, também já estão disponíveis para utilização de seus consumidores.

Além dos aplicativos, existe outro fator que potencializa o aparelho digital, as redes sociais, criadas com a finalidade de entreter e permitir a comunicação fácil e rápida entre os indivíduos que a utilizam. Assim, comunicar-se por meio de "aparelhos celulares" em nossa sociedade não é mais sinônimo de realizar uma ligação telefônica. A comunicação escrita, rápida, econômica e prática por meio das redes sociais tem conquistado seu espaço dentro destas tecnologias digitais. Nessa ótica, um dos aplicativos com maior download e mais utilizado pelos adeptos dos "celulares inteligentes", o WhatsApp tem sido o grande motivador desta nova forma de comunicação e relacionamento virtual. Por meio de grupos de amigos, trabalho ou assuntos em comum, grupos de conversas são criados a fim de proporcionar "encontros" e conversas, sem necessariamente, estar em contato corporal direto com outros indivíduos, ou ainda momentos reservados em conversas individuais e privativas.

Diante de todo este contexto, não há como ignorar que esta ferramenta tecnológica digital está fortemente amalgamada ao cotidiano da maioria da população brasileira. Criou-se uma "Cultura digital” em nossa sociedade. Entendendo esse aspecto cultural em que nossa sociedade perpassa, não há como ignorar sua utilização nos ambientes escolares. Acreditamos que esta ferramenta tecnológica pode auxiliar e contribuir nos processos de aprendizagem dos alunos, permitindo diferentes modos de ensinar e aprender, e que sejam atraentes aos alunos, quebrando assim paradigmas na educação.

\footnotetext{
4 Disponível em: 〈https://www.youtube.com/watch?v=6UhlZVzeysA $>$.
} 
Nesse sentido, várias são as funções que um smartphone possui e muitos delas ainda nem foram explorados. Assim, a proposta apresentada neste texto é oriunda de uma pesquisa de Mestrado que resultou em uma dissertação que teve por objetivo buscar integrar os smartphones nos processos de ensino de matemática. Portanto, o objetivo do presente artigo é refletir sobre uma atividade de investigação que uma turma de alunos do nono ano do Ensino Fundamental desenvolveram utilizando seus smartphones à luz da etnomatemática. Por entender que os smartphones estão fortemente ligados à cultura de nossa sociedade, utilizamos o campo da etnomatemática em seus entrecruzamentos com as tecnologias digitais, como base para sustentação teórico-metodológica da pesquisa.

Munidos das ideias até aqui expostas, a prática pedagógica foi desenvolvida em uma escola pública de um pequeno município localizado na Região do Vale do Taquari, no estado do Rio Grande do Sul, com uma turma de nono ano do Ensino Fundamental. Salientamos que as atividades a seguir expostas são fruto de uma dissertação desenvolvida no âmbito de Mestrado Profissional em Ensino de Ciências Exatas. Assim, abordaremos neste trabalho, duas das atividades desenvolvidas durante toda a pesquisa.

A seção a seguir é dedicada aos aportes teóricos que sustentaram a investigação a saber, o campo da Etnomatemática em seus entrecruzamentos com as tecnologias digitais.

\section{O campo da Etnomatemática e possíveis entrecruzamentos com as tecnologias digitais}

A Etnomatemática surgiu como campo da Educação Matemática em meados da década de 1970 com os trabalhos do professor e pesquisador Ubiratan D'Ambrosio (ROSA; OREY, 2006), o qual hoje é considerado Pai da Etnomatemática (GERDES, 2010). Ao criar o termo Etnomatemática, D'Ambrosio (2013) renuncia privilegiar ou aceitar que em um mundo com povos e sociedades tão diferentes, exista apenas uma matemática. Ou ainda, 
afirma que apenas a matemática - praticada somente por matemáticos (acadêmica ou escolar), sejam únicas e satisfatórias para a vida em sociedade. Para ele, existem outras matemáticas imbricadas em contextos culturais distintos, tais como, a matemática "praticada por grupos culturais, tais como comunidades urbanas e rurais, grupos de trabalhadores, classes profissionais, crianças de certa faixa etária, sociedades indígenas, e tantos outros grupos que se identificam por objetivos e tradições comuns aos grupos" (D’AMBROSIO, 2013, p. 9). Para o autor

A cultura, que é o conjunto de comportamentos compatibilizados e de conhecimentos compartilhados, inclui valores. Numa mesma cultura, os indivíduos dão as mesmas explicações e utilizam os mesmos instrumentos materiais e intelectuais no seu dia a dia. (D’AMBROSIO, 2013, p. 35-36).

Nesse sentido, ao criar a palavra Etnomatemática, D’Ambrosio busca em meio a aspectos culturais - verificar como povos, tribos, e sociedades utilizam a matemática, em seus diversos modos de saber e fazer, lidar, matematizar, contar, medir, racionalizar, inferir, calcular (D'AMBROSIO, 2013). Conforme Vergani (2007, p. 27) “a escola não poderá continuar a ignorar/desprezar a indissociabilidade homem/cultura: é nela que a criança funda a sua dignidade, a confiança no seu saber, o valor da sua experiência e do seu processo singular de autonomia”.

Assim, a Etnomatemática tem sua origem nas raízes descritas por D’Ambrosio (2013), onde o autor descreve o conjunto de significados que deu origem ao termo Etnomatemática, afirmando que

O conjunto desses instrumentos se manifesta nas maneiras, nos modos, nas habilidades, nas artes, nas técnicas, nas ticas de lidar com o ambiente, de entender e explicar fatos e fenômenos, de ensinar e compartilhar tudo isso, que é o matema próprio ao 
grupo, à comunidade, ao etno. Isto é, na sua etnomatemática. (D'AMBROSIO, 2013, p. 35-36, grifos do autor)

Corroborando com as ideias de D’Ambrosio, Knijnik et al. (2013) afirmam que a etnomatemática tem por objetivo valorizar toda e qualquer manifestação matemática, seja ela relacionada à matemática ensinada nas escolas ou não. Para as pesquisadoras, "não existe uma única Matemática, essa que chamamos 'a' Matemática” (KNIJNIK et al., 2013, p. 28) e sim, 'as matemáticas', relatando que além da matemática acadêmica, existem também a matemática "presente nas brincadeiras infantis e a Matemática praticada pelas mulheres e homens para atender às suas necessidades de sobrevivência” (KNIJNIK et al., 2013, p. 23).

Por reconhecer e valorizar os aspectos culturais em que determinados grupos estão inseridos e com relação ao atual contexto da educação matemática no cenário nacional, D’Ambrósio expressa:

A educação formal é ainda dominada pelo material escrito e impresso, enquanto a educação não-formal tem papel dominante, ajudando os indivíduos a se comunicar no mundo em que vivem, pelos meios de comunicação, gerando destreza e observando informações processadas. Esse é, provavelmente, o maior desafio para os educadores de ciência, tanto em países desenvolvidos como naqueles em desenvolvimento. (D'AMBROSIO, 2002, p.33)

Nesse sentido, Conrado (2006), destaca que é tempo de buscar novos horizontes, discutir e propor novos caminhos para o ensino da matemática. Segundo ela, os pesquisadores etnomatemáticos têm procurado apontar para novos caminhos que, via diálogo, "possibilitem a troca de conhecimentos e saberes entre escola-sociedade e professor-educando de maneira que os alunos possam abandonar a passividade e a reprodução de procedimentos impostos anteriormente a educadores" (CONRADO, 2006, p. 77). Ademais, ainda para a autora, tal processo permitiria que os docentes deixassem de 
agir como meros transmissores de conhecimento" (Ibidem, p. 77, grifos da autora).

Tais propostas passam pela inserção dos recursos tecnológicos em sala de aula. Em efeito, ao olharmos para nossos alunos, é possível verificar o quão desenvolvidos tecnologicamente estão, e o quanto utilizam e se prendem a tais artefatos. Praticamente, todos os adolescentes e jovens independente da classe social - possuem um aparelho de smartphone e a todo instante acionam seus dispositivos móveis por meio de notificações recebidas, ou mesmo para verificar o horário. Para Borba, Silva e Gadanidis (2014, p. 42),

As tecnologias digitais móveis - internet, celular, tablets - estão modificando as normas que vivemos, os valores associados a determinadas ações. Mais uma vez isso acontece em ritmo diferente fora e dentro da escola. Assim o abismo entre práticas que alunos e professores têm fora da escola e dentro da mesma instituição aumenta.

Desta forma, refletimos sobre a temática indagando-nos, de que se tal artefato tecnológico está tão presente na vida de nossos alunos, o mesmo pode - se ocorrer planejamento, objetivos bem definidos e estratégias de ensino bem elaboradas - ser utilizado como uma ferramenta importante para melhorar os processos de ensino e de aprendizagem de matemática. Nesse sentido, os autores afirmam que há muito que explorar e trabalhar por meio destas tecnologias digitais, visto que tais ferramentas estão associadas e conectadas a internet móvel, podendo acessar conteúdos e dados de maneira rápida e prática sem, necessariamente, precisar estar em um local específico. Assim,

A utilização de tecnologias móveis como laptops, telefones celulares ou tablets tem se popularizado consideravelmente nos últimos anos em todos os setores da sociedade. Muitos de nossos 
estudantes, por exemplo utilizam a internet em sala de aula a partir de seus telefones para acessar plataformas como o Google. Eles também utilizam as câmeras fotográficas ou de vídeo para registrar momentos das aulas. Os usos dessas tecnologias já moldam a sala de aula, criando novas dinâmicas, e transformam a inteligência coletivo, as relações de poder (de Matemática) e as normas a serem seguidas nessa mesma sala de aula (BORBA; SILVA; GADANIDIS, 2014, p. 77).

Acreditamos, portanto ser válida a referida proposta, buscando utilizar as tecnologias, em especial os smartphones, em sala de aula, mediados pela perspectiva Etnomatemática, pois segundo D’Ambrosio (2013, p.46-47), “a proposta pedagógica da etnomatemática é fazer da matemática algo vivo, lidando com situações reais no tempo [agora] e no espaço [aqui]. E, através da crítica, questionar o aqui e agora". Ainda para ele, "ao fazer isso, mergulhamos nas raízes culturais e praticamos dinâmica cultural. Estamos, efetivamente, reconhecendo na educação a importância das várias culturas e tradições na formação de uma civilização, transcultural e transdisciplinar" (Ibidem, p.47).

Frente a este desafio, abordado neste referencial teórico, de entrelaçar a etnomatemática com as tecnologias digitais, buscaremos na seção seguinte relatar os caminhos percorridos, bem como a proposta para a efetivação da prática pedagógica.

\section{Metodologia da prática investigativa e seus resultados}

Como frisado anteriormente, a pesquisa foi desenvolvida em uma turma de nono ano do Ensino Fundamental, em uma escola pública de um pequeno município pertencente a Região do Vale do Taquari, localizado no estado do Rio Grande do Sul. A prática pedagógica contou com a participação de dezessete alunos, com faixa etária média de 14 anos de idade. Cabe ressaltar que o pesquisador não era professor titular da turma 
sendo esta cedida por uma docente da área da Matemática, a qual buscou acompanhar as atividades desenvolvidas. A cedência da turma também se seu em função de que a escola em questão era parceira de um projeto maior - vinculado ao Programa governamental Observatório da Educação (Edital INEP/CAPES 049/2012) no qual o pesquisador estava inserido.

Buscamos, como apontam os referenciais teóricos do campo da etnomatemática, enveredar por uma pesquisa qualitativa e de inspirações etnográficas pois o pesquisador inseriu-se no contexto dos pesquisados bem como pela proximidade e relações de confiança estabelecidas com os pesquisados (D'AMBROSIO, 2013; D'AMBROSIO, 2012; ALVES, 2010). D’Ambrosio (2012, p. 93), afirma que

A pesquisa qualitativa é muitas vezes chamada etnográfica, ou participante, ou inquisitiva, ou naturalista. Em todas essas nomenclaturas, o essencial é o mesmo: a pesquisa é focalizada no indivíduo, com toda a sua complexidade, e na sua interação com o ambiente sociocultural e natural. O referencial teórico, que resulta de uma filosofia do pesquisador, é intrínseco ao processo. Naturalmente a interação pesquisador-pesquisado é fundamental e por isso essa modalidade é muitas vezes chamada pesquisação. Não é surpreendente o fato de essa modalidade de pesquisa ser típica dos antropólogos.

Por conta de questões vinculadas à ética em pesquisa, os pais dos estudantes assinaram o Termo de Consentimento Livre e Esclarecido tendo em vista que os alunos eram, à época do estudo, menores de idade. Ademais, a escola, como referido anteriormente, era considerada parceira do projeto, razão pela qual a direção já havia assinado um Termo de Adesão ao projeto no início da pesquisa maior. A intervenção pedagógica foi desenvolvida por meio de oito atividades, distribuídas em vinte e seis horas-aula. Neste artigo, serão abordadas duas. A primeira diz respeito a uma roda de conversas e discussões com o intuito de verificar as diversas opiniões e 
conceitos que os alunos possuem sobre a temática dos aparelhos smartphones. Em meio às discussões, foram trazidas para esta aula, pelo próprio professor/pesquisador, algumas notícias, reportagens e dados estatísticos, gráficos sobre aspectos que envolvem o aparelho, a fim de auxiliar as discussões. Ato contínuo, os alunos foram desafiados a formarem quatro grupos e realizarem uma tarefa de pesquisa acerca de um conjunto de temas propostos: i) Resgatar aspectos históricos e o surgimento dos smartphones; ii) Verificar os benefícios da utilização deste artefato tecnológico; iii) Identificar malefícios oriundos do uso contínuo desta tecnologia; iv) Como a sociedade utiliza este aparelho e como ocorre a comunicação atualmente. Cada grupo teve autonomia para a escolha do tema e de como apresentar os resultados da pesquisa. Assim, num segundo momento esta tarefa teve por finalidade a socialização quanto aos resultados obtidos nas anteriores realizadas, bem como abordar e discutir com a turma sobre o material que fora socializado pelos grupos.

A coleta de dados foi efetivada a partir dos seguintes instrumentos: i) diário de campo do pesquisador; ii) gravação em áudio de todos os encontros; iii) registro das atividades desenvolvidas por meio de fotografias e filmagens; iv) coleta do material produzido pelos alunos inclusive a redação final elaborada pelos alunos acerca das práticas.

Para tanto, ao iniciar esta pesquisa de cunho etnográfico, inicialmente, propusemo-nos a conhecer os sujeitos participantes e estabelecer com eles o primeiro contato. Desconhecidos, aluno-professor e/ou professor-aluno, procuramos "quebrar" a timidez mediante a introdução de um diálogo. Após um tempo de contato e algumas discussões travadas acerca da problemática do uso dos smartphones (movidas por vezes mediante reportagens e dados estatísticos por meio de gráficos de situações voltadas à utilização dos aparelhos celulares), surgiu a necessidade de pesquisar mais sobre a temática acerca de aspectos 'chaves' emergentes deste debate.

Em vista disso, procuramos desenvolver uma prática que explorasse ainda mais tais elementos, bem como valorizasse e 'desse voz' aos alunos 
para expressarem seus pontos de vistas e anseios tanto na disciplina de Matemática quanto no uso de seus smartphones. Ao pensar assim, desafiamo-los a realizarem uma pesquisa abordando quatro pontos relevantes conforme relatado anteriormente (itens: i, ii, iii, e iv).

Diante desse cenário, dividimos a turma em quatro grupos e conferimos a cada um a responsabilidade de trabalhar um dos temas propostos. Ato contínuo, combinamos sobre o tempo, a ordem e a data das apresentações. Concedemos autonomia para realizar suas pesquisas e organizar o modo de socializar com os demais colegas de classe. Assim, o primeiro grupo ficou responsável por abordar toda a trajetória histórica do surgimento dos celulares, bem como a sua evolução. As equipes optaram por uma apresentação oral, utilizando a multimídia para projetar imagens de vários exemplares desses artefatos tecnológicos encontrados na internet, fazendo uma espécie de 'linha do tempo' desde a implantação da telefonia fixa criada por Alexander Graham Bell, da invenção do celular por Martin Cooper até chegar aos smartphones. No momento em que as imagens dos primeiros aparelhos foram exibidas, muitos alunos demonstraram - por meio de gestos e expressões - espanto e curiosidade quanto aos modelos e dados fornecidos pelos apresentadores.

Convém lembrar que retroceder ao passado, compreender o processo histórico do surgimento e evolução da telefonia móvel, em muitos casos, são abordagens importantes para o campo da Etnomatemática. Segundo D’Ambrosio, (2016, p. 5, tradução e grifos nossos), para discutir a Etnomatemática, é mister "refletir sobre nossos desejos, metas e ações que estão todas no presente. Para isso, contamos com experiências passadas. Assim, o presente é a interface entre passado e futuro" 5 .

Nesse sentido, utilizamo-nos das ideias de D’Ambrosio (2013, p. 17) onde o autor afirma que para a Etnomatemática "é procurar entender o saber/fazer matemático ao longo da história da humanidade,

$5 \quad$ Original: "reflect on our wishes, goals, and actions, which are all in the present. In order to do that, we rely on past experiences; thus, the present is the interface between past and future". 
contextualizado em diferentes grupos de interesse, comunidades, povos e nações". Frente à afirmação do autor, podemos compreender a importância da realização desta atividade, a luz da Etnomatemática, permitindo aos alunos maior compreensão e percepção da realidade hoje vivida por eles.

Finalizada a apresentação, disponibilizamos um tempo para as discussões, algumas transcritas a seguir. Por questões de ética em pesquisa, nomeamos os estudantes com letras do alfabeto.

Aluno J: Deus me livre... imagina "sor" ter que carregar um 'tijolão' desses pra cima e pra baixo. Mais de meio quilo um celular, tá loco!

Aluno $K$ : É que na época, esse celular não foi desenvolvido pra tudo isso que a gente usa hoje. Era só pra ligar... e hoje o que a gente quase não faz é isso. Aluno $J$ : Era muito feio.

Aluno $H$ : Graças ao avanço, hoje eles estão bem mais baratos. Tipo, tá mais acessível. Hoje praticamente todo mundo tem celular.

Professor: Será que ele [Martin Cooper] imaginava que hoje quase todos teriam acesso a um celular? Ou, ainda, que o celular possibilitaria as funções que hoje estão disponíveis para nós?

Aluno $M$ : Acredito que não. Se não ele mesmo já teria feito.

Aluno G: Mas na época isso foi um grande avanço. Pensa, é quase inacreditável se for pensar, como eu vou falar com alguém tipo de outra cidade no mesmo momento?

Aluno $H$ : É verdade. Acho que ele nem sonhava com isso.

Aluno J: Ainda bem que hoje é diferente!

As enunciações dos alunos, além do espanto, transmitiam um sentimento de 'rejeição' pelos modelos antigos e 'alívio' pelo avanço que os celulares haviam alcançado. Não nos sentimos aptos a afirmar se esse momento contribuiu beneficamente ou não para o prosseguimento das atividades. Contudo, nosso instinto quanto pesquisadores nos induzia a pensar que ele foi importante para aqueles adolescentes. A afirmação proferida pela aluna J “ainda bem que hoje é diferente!", apoiada pelos demais colegas, levou a turma a perceber que somos 'dependentes' desse artefato tecnológico. A esse respeito, Borba (2012) afirma que estamos imbricados de tecnologia a ponto de esta ser considerada uma extensão de nosso corpo. Portanto, essa retrospectiva veio ao encontro das ideias 
expressas por Bortoli, Marchi e Giongo (2016, p. 51), ao defenderem que para a Etnomatemática:

$$
\begin{aligned}
& \text { Interligar o pensamento passado ao presente não significa } \\
& \text { retroceder nos conteúdos a serem vistos, mas sim fazer um } \\
& \text { retrospecto dos acontecimentos com os alunos, evidenciando as } \\
& \text { necessidades e os motivos que fundamentaram e proporcionaram o } \\
& \text { conhecimento da época. }
\end{aligned}
$$

Dando sequência às atividades, a segunda apresentação abordou os benefícios do uso dos smartphones. Com o auxílio do projetor, elencaram sete itens, a saber:

i) Comunicação Instantânea: por meio de ligação, internet ou redes sociais;

ii) Economia de Dinheiro: justificativas e comparação com a telefonia fixa;

iii) Segurança: utilizados em casos de emergência para acionar a polícia ou solicitar auxílio e função GPS para encontrar ou socorrer alguém;

iv) Negócios: possibilita reunião por meio de videoconferência, bem como acesso a e-mails, documentos online, contas de banco e movimentação financeira via aplicativo;

v) Aprendizagem Móvel: acesso à internet móvel, aquisição e leitura de livros e material científico disponibilizado em formato de pdf.

vi) Aprendizagem Individualizada: flexibilidade em estudar singularmente, busca de arquivos e realização de pesquisas, podendo cada aluno 'ditar' seu ritmo de estudo;

vii) Aprendizagem em qualquer hora e lugar: a educação e os momentos de estudo podem ocorrer em ambientes não escolares. Por meio de aplicativos, baixam-se lições e conteúdos similares e/ou diferentes aos abordados em sala de aula. 
Após a explanação dos sete pontos elencados pelos alunos, novamente propusemos um momento de discussões sobre o trabalho apresentado e o tema discorrido. Entretanto, a turma não emitiu comentários, e o período de aula acabou. Embora a ausência de relatos posteriores, durante a apresentação do grupo, os demais alunos demonstraram interesse e, com frequência, balançavam a cabeça, sinalizando que concordavam com as ideias expostas.

$\mathrm{Na}$ aula seguinte, tentamos mais uma vez introduzir um debate; porém, sem sucesso. Entendendo que o 'calor' do assunto já não era mais o mesmo e, após uma tentativa frustrada de retomar as discussões, decidimos prosseguir com a próxima apresentação. O grupo responsável por expor os malefícios se tornou um exemplo nítido do tema que lhe fora proposto. $\mathrm{Na}$ apresentação, seus componentes utilizaram uma reportagem exibida no programa de televisão da Rede Globo, 'Fantástico', que havia explanado os danos do uso de smartphones, principalmente em ambientes escolares.

Contudo, o vídeo fora editado pelos integrantes do grupo, que utilizaram as imagens de um colega da sala de aula, retiradas do Facebook quando era mais jovem, as quais, durante a reportagem, surgiam como 'flashes'. Visivelmente, a seleção das fotos teve o intuito de provocar risos generalizados do colega que não pertencia ao grupo responsável pela apresentação. O ato foi tão grave que se caracterizou como bullying.

Ao término da apresentação, questionamos, com firmeza, os integrantes do grupo sobre o significado do vídeo e a turma percebeu que o fato deixou de ser 'engraçado'. Para uma melhor compreensão sobre o ocorrido, transcrevemos parte do diálogo.

Professor: O que significa este vídeo?

Aluno $M$ : A gente pegou o vídeo que fala sobre os malefícios, "sor"..

Professor: Quem editou o vídeo?

Aluno M: A gente mesmo.

Professor: O que levou vocês a fazerem isso?

Aluno $F$. A gente achou que ia ficar mais dinâmico e engraçado.

Professor: Vocês ficaram responsáveis por trazer questões acerca do malefício do uso de celulares e acabaram colocando em prática literalmente. 
Aluno M: Não, "sor"...

Professor: Vocês pediram autorização ao colega para expor a imagem dele em público e da maneira como o fizeram?

Aluno B. Ué professor, se tá no Facebook, então todo mundo pode pegar. Se não quer que ninguém veja ou copie a foto, então não posta!

Professor: Vocês acham que podem pegar fotografias de alguém sem permissão e utilizá-las para gracinhas? Isso é correto? Sabem como isso se caracteriza?

Aluno M: Foi mal professor, mas é que...

Aluno J: Isso é racismo!

Professor: Isso é Bullying! Já ouviram falar?

Aluno $B$. Ah, isso não é não, foi só uma brincadeira...

Professor: Aluno H, alguém pediu sua autorização para utilizar as fotos?

Aluno $H$ : Não...

Professor: Você gostou da "brincadeira"?

Aluno H: Não... [demonstrando constrangimento em sua feição].

Professor: Precisamos tomar cuidado! Isso é algo muito sério o que aconteceu aqui. Não é porque as fotos estão nas redes sociais que podemos utilizá-las da maneira como bem queremos... Isso também serve de alerta para que nós tenhamos cuidado com tudo o que postamos nas redes sociais. Uma imagem indevida pode se espalhar rapidamente... E também pode machucar e causar sérios problemas, até mesmo, judiciais.

$\mathrm{O}$ fato nos fez refletir e questionar alguns aspectos importantes; entre eles, os malefícios que a ferramenta em questão pode disseminar se utilizada de maneira imprópria, bem como o papel do professor pesquisador diante de uma situação como a ocorrida. Embora o grupo tentasse argumentar que não tencionava praticar bullying; seus componentes perceberam que o comportamento fora inadequado e que deram um mau exemplo de como usar a tecnologia.

Nesse sentido, reportamo-nos as ideias de Gerdes (2010), ao fazer menção sobre a importância da consciência do professor frente as atividades propostas centradas na Etnomatemática, e suas consequências caso não consiga lidar com tais resultados/ações negativas. Nesse sentido, o autor afirma que

Cada povo, cada cultura e cada subcultura, incluindo cada grupo social - por exemplo, cesteiras (os) e oleiras (os) nos exemplos dados - e cada indivíduo, constrói e desenvolve a sua matemática, de certa maneira, particular. Quando um (a) professor (a) não está 
consciente de como diferenças culturais podem gerar desenvolvimentos diferentes na matemática, isto poderá levar a problemas significativos para os (as) aprendizes da matemática (GERDES, 2010, p.160, grifos do autor).

Posto isso, no excerto anterior, podemos ainda verificar que, no início, os apresentadores tentaram justificar seu comportamento, não concordando com a ideia de que estavam praticando um ato maléfico e ofensivo. A atitude do grupo me levou a pensar novamente sobre o papel e a responsabilidade do professor e da escola na inserção e utilização correta das tecnologias digitais nas salas de aula. Em função da gravidade da situação, conversamos com a Coordenação Pedagógica que, posteriormente, realizou um trabalho nas turmas acerca de redes sociais e bullying.

Nesse momento, reportamo-nos às ideias de Borba, Silva e Gadanidis (2014) quando declaram que as escolas têm procurado proibir a utilização de aparelhos celulares em oposição de buscar alternativas para melhorar o ensino e discutir seu uso. Nesse sentido, Kenski (2014, p. 89) afirma que, no trabalho que envolve as tecnologias,

O maior desafio nessas relações é garantir a aprendizagem de todos como pessoas melhores, para que possam convergir suas atenções e interesses em aprender a lidar com as informações e com as demais pessoas com respeito, civilidade, atenção, cortesia, postura crítica e colaboração.

Ao retomarmos as atividades, assistimos à última apresentação, cuja temática foi o modo como as pessoas utilizavam e se relacionavam fazendo uso de seus celulares. O grupo responsável decidiu produzir um trabalho diferenciado, elaborando um questionário e colocando־o nas redes sociais, em especial no Facebook, para que os colegas o respondessem. Porém, não obteve o sucesso esperado, já que a turma não participou da enquete. Em 
vista disso, seus integrantes entrevistaram três amigos e, por meio de um gravador de áudio, repassaram os depoimentos aos demais alunos.

Finda a apresentação, os colegas do grupo consideraram o número de entrevistas insuficientes para comprovar possíveis resultados ou fornecer indícios sobre as questões que envolviam a temática. Assim, propuseram analisar a elaboração do questionário e refazê-lo, pois, de acordo com eles, era extenso demais, o que lhes causava certa 'aversão' por respondê-lo. Tal situação emergiu em outra ação de pesquisa que envolveu o desenvolvimento deste novo questionário previamente planejado pelos alunos e respondido pelos demais alunos da própria escola. Os resultados advindos desta proposta abordaram as construções gráficas, conforme expresso em Gerstberger e Giongo (2018).

A segunda atividade aqui abordada também gerou muitas discussões tendo em vista que se tratava de questões vinculada à matemática financeira. Em efeito, propusemos à turma uma investigação com o intuito de coletar dados referentes a modelos de smartphones, em um comércio local por meio da simulação/compra do artigo em questão. Os alunos, na ocasião, desempenharam papel de consumidores, buscando extensa quantidade de informações sobre os aparelhos. Os estudantes fizeram uso de seus aparelhos por meio do bloco de notas, gravador e fotos. No retorno à sala de aula, foram divididos em três grupos, com a tarefa de elaborar e apresentar as conclusões de suas investigações.

O grupo A evidenciou que, apesar de terem gostos diferentes, a estética do aparelho foi um dos itens observados. Acrescido a este, a quantidade de memória para o armazenamento de dados e vídeos como fotos e vídeos também foram considerados. Os integrantes do grupo mencionaram ser comum a prática de "encher a memória" do aparelho e deste começar a "travar", fato que os deixava insatisfeitos. A pouca durabilidade da bateria também foi explicitada, sendo que um dos alunos comentou que "sobre a bateria, a mulher [atendente] nos falou que dependeria a forma de como se usa o celular". 
Quanto à forma de pagamento, o grupo compreendeu a substancial diferença entre o pagamento à vista e a prazo. Em efeito, como bem apontou um dos alunos, "preço à vista era $\mathrm{R} \$ 3349,00$ e a prazo, $\mathrm{R} \$ 5098,00$, parcelado em 20 vezes”. A posteriori, amparados pelas gravações em vídeo e áudio, problematizamos qual seria a melhor forma de pagamento. Os alunos foram unânimes em responder que o juro estava muito alto, sendo que o valor pago a mais era maior do que a metade à vista. Espantado, um dos estudantes comentou que "com cinco mil eu compro uma moto, professor, é muito dinheiro!".

A qualidade da câmera fotográfica e do vídeo foi um dos itens mais considerados pelo grupo B. Como bem evidenciou outro estudante, "a gente acha que o celular sem câmera não tem graça professor, aí a gente olhou a melhor qualidade e preferiu escolher os três aparelhos que melhor tivessem as câmeras". Da mesma forma que o grupo anterior, este analisou a condição financeira dos integrantes para escolher um modelo em torno de $\mathrm{R} \$ 849,00$, parcelados em seis vezes.

Por fim, o grupo C também considerou a câmera fotográfica e o vídeo importantes, sobretudo com ênfase na memória. Entretanto, consideraram os valores financeiros. Ademais, o mesmo abordou a questão da garantia, enfatizando que a do carregador "descobrimos que a garantia do carregador do celular possui três meses de garantia. Na verdade, todos os acessórios do celular possuem três meses de garantia, e o celular, um ano" (aluno K).

Finda a atividade, alguns relatos de estudantes evidenciaram a produtividade da pesquisa de preços, tendo em vista que "foi uma experiência muito boa, deu para a gente ter um pouco mais de noção nas compras, e eu acabei perguntando coisas que eu nunca pergunto, tipo câmera, áudio, essas coisas" (aluno K). Em adição, outro afirmou que "eu achei da hora, porque estou a fim de comprar um celular para mim, e aproveitei e já fiz a pesquisa pra mim mesmo" (aluno F).

Portanto, ao analisarmos esta atividade, nos posicionamos favoráveis acerca da importância de trazermos aspectos culturais fortemente 
imbricados no cotidiano de nossos alunos para dentro da sala de aula, vinculando-os aos conteúdos matemáticos propostos em nosso currículo. Entendemos e constatamos nesta atividade que o ensino baseado nas raízes da Etnomatemática - conforme descrito no referencial teórico por D’Ambrosio (2013) - permite uma maior assimilação do conteúdo e de seu cotidiano permitindo aos discentes maior assimilação entre conteúdo e prática, "fazendo conexões diretas entre a matemática da escola acadêmica e as práticas culturais matemáticas desenvolvidas, praticadas e usadas localmente"6 (ROSA e OREY, 2015, p. 590, tradução minha).

Frente a este cenário, entendemos que ensinar a matemática centrada nos conceitos e ideias da Etnomatemática, vai muito além de ensinar para que serve o conteúdo abordado em sala. É permitir reflexões sobre a importancia de compreender que a matemática - independente de formulas ou regras matemáticas - é algo que menisfesta-se em nosso cotidiano e que estamos a todo momento imbricados e entrelaçados com esta ciência.

Neste sentido, ancoramonos nas ideias de Alves (2010), ao defender que para a Etnomatemática o interesse não está interessada em apenas em apenas abordar somente a matemática do "para que serve", ou ainda, trazer o cotidiano para dentro da sala de aula. Mas afirma que

Não se pretende trabalhar com a matemática só do para que serve, reduzir a Matemática às práticas cotidianas, pois se assim fosse, teríamos que de certa forma abandonar a sala de aula. Mas, por outro lado, se privilegiamos apenas uma única prática, teremos sempre uma insatisfação por parte dos alunos, sendo que é possível trabalhar com o formal, mas trazer para a sala de aula o informal, já que numa mesma sala de aula, temos alunos com diferentes culturas. (ALVES, 2010, p. 49)

\footnotetext{
${ }^{6}$ Original: "by making direct connections between academic school mathematics to the mathematical cultural practices developed, practiced, and used locally".
} 
$\mathrm{Na}$ última seção deste artigo, tecemos alguns comentários com o propósito de seguir problematizando como práticas pedagógicas alicerçadas teoricamente no campo da etnomatemática podem fomentar outros modos de ensinar e aprender matemática.

\section{Conclusão}

Inicialmente, entendemos que as duas atividades aqui explicitadas contribuíram para que os estudantes pudessem dar sentido às aulas da disciplina Matemática. Nessa ótica, partilhamos do mesmo pensamento de Bortoli, Marchi e Giongo (2016) acerca da importância de conceder um sentido e contextualizar os conteúdos a serem abordados em sala de aula. Para as autoras,

A valorização das habilidades matemáticas presentes em nosso cotidiano pode enriquecer o conhecimento matemático escolar, dar sentido ao que é estudado, possibilitando a identificação e o estabelecimento de relações entre esses diferentes saberes. Ao educar nessa perspectiva, procuramos instigar os alunos a serem cidadãos críticos e pesquisadores, com condições de interagir com o meio em que estão inseridos (BORTOLI, MARCHI e GIONGO, 2016, p. 26-27).

A criticidade de que falam as autoras pode ser evidenciada, sobretudo, na posição dos estudantes durante o debate efetivado após a pesquisa de preços dos smartphones. De fato, quando, dentre outros, um dos estudantes evidenciou que "professor, eu nunca perguntei essas coisas quando comprei meus outros celulares", parece-nos que está evidente o papel social do ensino de Matemática na Escola Básica.

Evidentemente, durante o processo, algumas limitações e tensões foram percebidas, com ênfase na questão do bullying. Entretanto, em vez de nos imobilizar, tais situações podem ser produtivas para essas discussões 
sejam fomentadas nas escolas. Com isso, nossos estudantes certamente estarão em condições de fazer uso das redes sociais de modo responsável. Como bem apontam Borba e Lacerda (2015, p. 500, grifos nossos) "se não queremos o celular nas aulas devido a condutas inadequadas dos nossos alunos precisamos então educá-los de forma a integrar essa tecnologia móvel à cultura escolar e ao material didático dos alunos".

Outra situação que alude a limitações diz respeito ao fato de que alguns estudantes mostraram-se, principalmente no início da pesquisa/intervenção, apáticos e pouco propensos a interagir com os demais. Nossa hipótese é que tal postura se deva às poucas experiências semelhantes que tiveram ao longo de sua vida estudantil, razão pela qual entendemos ser de suma importância que pesquisas neste campo continuem a apontar novos modos de ensinar e aprender matemáticas.

\section{Referências}

ALVES, E. R. Etnomatemática. Multiculturalismo em sala de aula: a atividade profissional como prática educativa. São Paulo: Porto de Idéias, 2010.

BORBA, M. de C. Humans-with-media and continuing education for mathematics teachers in online environments. ZDM, Berlim, v. 44, pp. 801-814, 2012.

BORBA, Marcelo de C.; LACERDA, Hannah D. G. Políticas públicas e tecnologias digitais: um celular por aluno. Educação Matemática Pesquisa. São Paulo. Volume 17, n.3 pp. 490-507, 2015.

BORBA, M. de C.; SILVA, R. S. R. da; GADANIDIS, G. Fases das tecnologias digitais em Educação Matemática - Sala de aula e internet em movimento. $1^{\mathrm{a}}$ Ed. Belo Horizonte: Autêntica Editora, 2014.

BORTOLI, G.; MARCHI, M. I.; GIONGO, I. M. Uma abordagem histórica no ensino da trigonometria. $1^{\mathrm{a}}$ Ed. Curitiba: Appris, 2016.

CONRADO, A. L. Etnomatemáticas: sobre a pluralidade nas significações do programa etnomatemática. IN: RIBEIRO, J. de P. M. R.; DOMITE, M. do C. S.; FERREIRA, R. (orgs.) Etnomatemática: papel, valor e significado. 2. ed. Porto Alegre: Zouk, 2006. p. 75-87 
D'AMBROSIO, U. Etnomatemática. Um enfoque antropológico da matemática e do ensino. In: FERREIRA, M. L. (Org). Ideias matemáticas de povos culturalmente distintos. São Paulo: Global, 2002. (Série Antropologia e Educação).

2012 .

Educação Matemática: Da teoria a prática. $23^{\mathrm{a}}$ Ed. Campinas, SP: Papirus,

Etnomatemática - o elo entre as tradições e a modernidade. $5^{\mathrm{a}}$ Ed. Belo Horizonte: Autêntica Editora, 2013.

An Overview of the History of Ethnomathematics. In: ROSA, Milton; D'AMBROSIO, U.; OREY, D. C.; SHIRLEY, L.; ALANGUI, W. V.; PALARES, P.; GAVARETTE, M. E. Current and Future Perspectives of Ethnomathematics as a Program. Springer Open. ISBN 978-3-319-30119-8 ISBN 978-3-319-30120-4 (eBook), 2016.

GERDES, P. Da Etnomatemática a arte-design e matrizes cíclicas. $1^{\mathrm{a}}$ Ed. Belo Horizonte: Autêntica Editora, 2010.

GERSTBERGER, A.; GIONGO, I. Identificação e emergência de aspectos relacionados à cultura advinda da utilização de aparelhos celulares inteligentes. Alexandria, Florianópolis, SC. Volume 11, n. 1. pp. 309-332, 2018.

KENSKI, V. M. Tecnologias e tempo docente. Editora Papirus, Campinas-SP, 2014.

KNIJNIK, G.; WANDERER, F.; GIONGO, I. M.; DUARTE, C. G. Etnomatemática em Movimento. $2^{\text {a }}$ Ed. Belo Horizonte: Autêntica Editora, 2013.

ROSA, M.; OREY, D. C. Abordagens Atuais do Programa Etnomatemática: delineando um caminho para a ação pedagógica. Bolema, Rio Claro, SP, ano 19, n. 26, p. 19-48, 2006.

ROSA, M.; OREY, D. C. A trivium curriculum for mathematics based on literacy, matheracy, and technoracy: an ethnomathematics perspective. ZDM, Berlim, 47(4), 587-598, 2015. 